\title{
COMPLIANCE WITH THE OVERTIME PAY PROVISIONS OF THE FAIR LABOR STANDARDS ACT*
}

\author{
RONALD G. EHRENBERG and PAUL L. SCHUMANN \\ Cornell University \\ University of Minnesota
}

P

\section{INTRODUCTION} overtime pay premium required by the Fair Labor Standards Act (FLSA) from time and a half to double time in the hope that, when overtime hours were made more expensive, employers would be induced to reduce their usage of overtime and to increase their employment levels. That is, increasing the overtime premium is thought by some to be a way to stimulate employment growth and to reduce unemployment. ${ }^{1}$

If the overtime pay provisions of the FLSA are not fully complied with, the potential employment gain associated with any increase in the overtime premium will be reduced. Furthermore, since an increase in the overtime premium would increase the amount employers save by not complying with the legislation, such an increase might lead to a decrease in the compliance rate. This would further moderate the actual decline in overtime hours and the potential positive employment effects resulting from an increase in the overtime premium.

A number of data sources provide some information on compliance with overtime legislation. An early U.S. Department of Labor compliance survey indicated that 30 percent of the establishments in which overtime was worked were in violation of the overtime provisions of the FLSA and 5.9 percent of the employees working overtime were not paid in accor-

\footnotetext{
* Our research was conducted under a contract with the Minimum Wage Study Commission; however, the views expressed here are solely our own. A draft of this paper was written while Ehrenberg was a visiting professor at Tel-Aviv University.

1 See Ronald G. Ehrenberg \& Paul L. Schumann, Longer Hours or More Jobs? (1982), for an overview of the debate on the wisdom of instituting such a policy and a summary of the relevant empirical evidence.
}

[Journal of Law \& Economics, vol. XXV (April 1982)]

(C) 1982 by The University of Chicago. All rights reserved. 0022-2186/82/2501-0004\$01.50 
dance with the overtime provisions. ${ }^{2}$ More recently, Labor Department investigations in fiscal year (FY) 1977 of complaints of violations under the FLSA found a greater dollar volume of violations of the overtime pay provisions than they did of the minimum wage provisions. ${ }^{3}$ Finally, data from the annual May supplements to the Current Population Surveys (CPS) indicate that over the 1973-78 period, less than 43 percent of fulltime wage and salary workers who worked forty-one or more hours a week at one job reported receiving premium pay. ${ }^{4}$

Of course, many of the individuals who work long workweeks may work in noncovered employment where payment of an overtime premium is not required; only 58 percent of all wage and salary workers were covered by the overtime provisions of the FLSA in 1978..$^{5}$ Since one may reasonably conjecture that noncovered workers are more likely to work overtime, as their marginal costs of overtime hours are lower than those of otherwise identical covered workers, the data from the CPS cited above should be considered only suggestive and probably overstate the extent of noncompliance. Our objective in the next section is to analyze more carefully the May 1978 CPS and also the 1977 Michigan Quality of Employment Survey ( $Q E S$ ) data to obtain estimates of the extent of noncompliance with the overtime pay provisions, focusing on workers who can be identified with certainty as being covered by and subject to the overtime provisions of the FLSA.

Knowledge of the correlates of noncompliance may well be as important to policymakers as knowledge of the rate of noncompliance. While information on the latter may lead them to push for an increase in the resources devoted to enforcing compliance or for increases in the penalties for noncompliance or both, knowledge of the former is useful in deciding how the limited resources that the government has to assure compliance should be allocated. With this in mind, in Section III we describe our attempts to build and estimate a model of the determinants of noncompliance with the overtime pay provisions of the FLSA and discuss the conclusions that can be drawn from these efforts. ${ }^{6}$

${ }^{2}$ U.S. Wage and Hour and Public Contracts Divisions, Compliance Survey 1965 (Washington, D.C., 1966).

${ }^{3}$ U.S. Dep't Labor, Employment Standards Administration, Minimum Wage and Maximum Hours Standards under the Fair Labor Standards Act 1978 (Washington, D.C., 1978).

${ }^{4}$ George Stamas, Long Hours and Premium Pay, May 1978, 102(5) Monthly Lab. Rev. 41 (1979).

5 U.S. Dep't Labor, supra note 3.

${ }^{6}$ Our efforts in this section and the one that follows considerably generalize the work of Orley Ashenfelter \& Robert S. Smith, Compliance with the Minimum Wage Law, 87 J. Pol. Econ. 333 (1979). 
Our analyses in Sections II and III deal only with individuals who we can identify as being subject to the overtime pay provisions with certainty. However, for individuals employed in retail trade and selected service industries, coverage under the FLSA is partially based on whether the employer's annual sales exceed a critical value, and, at least in the $C P S$ data, such information is unavailable. One might speculate that noncompliance would be higher among employees subject to the overtime provisions in these industries than it would be elsewhere, as both employees' knowledge of their rights to receive overtime premiums of time and a half and employers' knowledge of their obligations to pay such premiums may be lower in these industries-especially in establishments whose sales just exceed the critical value. To test this conjecture, one must develop a method to estimate the extent of noncompliance in industries in which such size-class exemptions exist when data on the size of establishment in which each individual is employed are unavailable; this is done in Section IV. ${ }^{7}$ Finally, we briefly summarize the conclusions that can be drawn from our efforts.

\section{New Estimates of Noncompliance}

The May 1978 Current Population Survey contained data on 11,738 individuals who reported that they worked forty-one or more hours during the survey week for a single employer. It would be incorrect, however, to focus on this entire sample when discussing compliance with the overtime pay provisions, since there are numerous individuals who are not subject to the provisions. These include, but are not restricted to, supervisory employees, outside salespersons, employees in seasonal industries (including agriculture), state and local government employees, employees in small retail trade and service sector establishments, and some household workers.

Fortunately, it is possible to classify each individual who worked overtime as belonging to one of three groups: those who we believe are "definitely" subject to the overtime pay provisions; those who we believe are subject to the provisions with a known probability; and those who are either not subject to the provisions or for whom coverage probabilities cannot be determined. The assignment is based on an algorithm which makes use of knowledge of the various exemptions to the overtime provisions of the FLSA, of whether each individual was paid by the hour, and of the detailed three-digit census industry and occupation categories in which each individual is employed. In the case of individuals employed in

7 Ashenfelter \& Smith, supra note 6, confined their attention to the sector in which coverage could be determined with certainty. 
retail trade and selected service industries, where coverage under the overtime provisions was based on whether the establishment's sales exceeded $\$ 250,000$ per year in 1978 , each individual was assigned a probability of coverage equal to the fraction of employees in the three-digit industry who worked in establishments with sales of greater than $\$ 250,000$ in $1977 .{ }^{8}$ The latter information came from published volumes of the 1977 Census of Retail Trade and the 1977 Census of Selected Service Industries as well as from unpublished tabulations that were specially prepared for us by the census.

Details of the algorithm used to assign individuals to the three groups are contained in an appendix that is available from us. The procedure resulted in our classifying 3,231 individuals as being definitely subject to the overtime pay provisions and 535 individuals as being subject to the provisions with known probability. It is these two groups, which represent 32 percent of the individuals who reported working overtime, that we focus our attention on in the paper. This section and the next consider the "certain coverage" group, while Section IV considers the "known probability of coverage" or "partial coverage" group.

Individuals in the CPS sample reported whether they received any premium pay for overtime hours in excess of forty per week, not what their overtime pay premium was. While it is possible to construct an estimate of the overtime pay premium for a subset of individuals in the sample, this estimate is subject to considerable error. Because of this, we define noncompliance in the CPS data as failure to receive any premium pay for hours of work greater than forty hours per week. Since receipt of a premium of less than time and a half represents noncompliance also, such a definition clearly understates the extent of noncompliance. ${ }^{9}$

8 The establishment sales size test rose to $\$ 275,000$ on July 1,1978 , and has increased still further since then. However, since the CPS data are for May 1978, the $\$ 250,000$ figure is the correct one to use.

${ }^{9}$ Two problems should be noted with this definition. First, it ignores the possibility that the existence of the overtime pay premium may have caused some employers who otherwise would have worked their work forces overtime to avoid the use of overtime. Such employers would be complying with the legislation, but individuals employed in these firms would not be included in our sample. Although we return to this point in the next section, when we attempt to estimate whether government resources devoted to increasing compliance reduce the probability that an individual will work overtime, it should be understood that noncompliance is defined in this section to be conditional on individuals' working overtime. Second, there may be some measurement error in the reporting of hours of work. Some individuals who reported that they worked more than forty hours per week and failed to receive an overtime premium may actually have worked forty hours or less; inclusion of these individuals in our sample would cause us to overstate the noncompliance rate. In contrast, some individuals who reported that they worked forty hours or less and failed to receive a premium may actually have worked more than forty hours; exclusion of these individuals from our sample would cause us to understate the extent of noncompliance. 
TABLE 1

Estimates of Noncompliance with the Overtime Provisions of the FLSA: Complete Coverage Sample (Sample Size)

\begin{tabular}{|c|c|c|c|}
\hline \multirow[b]{2}{*}{$\begin{array}{l}\text { NONCOMPLIANCE } \\
\text { DEFINED AS: }\end{array}$} & \multicolumn{2}{|c|}{ MAY $1978 C P S$} & \multirow{2}{*}{$\begin{array}{c}1977 \text { MichIGAN } \\
\text { QES } \\
\text { Private } \\
\text { Only } \\
\text { (3) }\end{array}$} \\
\hline & $\begin{array}{l}\text { Private and } \\
\text { Federal } \\
\text { (1) }\end{array}$ & $\begin{array}{c}\text { Private } \\
\text { Only } \\
\text { (2) }\end{array}$ & \\
\hline $\begin{array}{l}\text { 1. Failure to receive any } \\
\text { premium pay for overtime } \\
\text { (hourly wage sample) } \\
\text { 2. Failure to receive a } \\
\text { premium of at least } 1.5 \\
\text { straight-time wage }\end{array}$ & $9.6 \%(3,231)$ & $8.9 \%(3,046)$ & $15.9 \%(69)$ \\
\hline
\end{tabular}

SourCES.-Authors' calculations from 1978 CPS Public Use data tapes; 1977 Michigan QES data tapes.

In Table 1 we focus on the individuals who we believe are definitely subject to the overtime pay provisions of the FLSA and, weighing each observation by its sample weight, compute an estimate of noncompliance; this is found in column 1. Defining noncompliance as failure to receive any premium pay for overtime, we find (row 1) that 9.6 percent of the individuals in the sample fell in this category. This number is higher than the estimates of noncompliance obtained in the 1965 Bureau of Labor Statistics compliance survey.

A second source of data on noncompliance is the 1977 Michigan $Q E S$. The $Q E S$ is a sample of over 1,500 employed adults, and the premium received for overtime work was explicitly reported for those in the sample who worked overtime. Unfortunately, most adults in the survey failed to work overtime, and, after applying our algorithm to isolate those individuals who were subject to the legislation with certainty (including the restriction that they were paid on an hourly basis), we wound up with a sample of only sixty-nine individuals. Of these individuals, however, almost 16 percent failed to receive a premium of time and a half (col. 3).

Although this estimate is quite precise, one should not place too much faith in its specific value because the sample may not be representative due to its small size. Nevertheless, it does suggest that the actual noncompliance rate in the complete coverage sector is probably fairly close to the lower-bound estimate of 9.6 that we obtained with the CPS data. We should reemphasize that the former figure refers to the fraction of those

While one hopes that these two sources of bias just offset each other, we have no strong reason to believe that this will (or will not) be the case. 
individuals working overtime who failed to receive any premium; it does not include those individuals who received overtime pay premiums of less than time and a half. To the extent that there are any individuals in this latter group, the actual noncompliance rate will be above 9.6 percent. ${ }^{10}$

\section{The Determinants of Noncompliance}

What are the factors that influence the probability that an individual who is working overtime and subject to the overtime pay provisions of the FLSA will be observed not being paid a premium of at least time and a half, as the FLSA calls for? An economic model of noncompliance should start from the proposition that an efficient solution requires that noncompliance will be observed only when the sum of the net benefits (benefits minus costs) to an employer and his employees from noncompliance exceeds zero. ${ }^{11}$ That is, the gains and losses from noncompliance faced by both parties in the employment relationship must be evaluated.

From the perspective of the employer, the benefits from noncompliance are the savings that accrue from his failing to pay workers working overtime a premium of at least time and a half. The costs to the employer of noncompliance include the costs of any increased employee turnover that may result from failure to pay legally required premium payments. These costs are likely to be higher for skilled workers than they are for unskilled workers and for workers that the employer expects (wants) to have long job tenure with the firm than they are for workers with short expected job tenure.

The costs of noncompliance also include any costs that would result if

10 One additional set of results warrants being briefly reported here. Analyses reported in the next section suggest that the noncompliance rate was higher in the federal sector than in the private sector. Some people may find it inconceivable that federal government agencies would fail to comply uniformly with federal legislation. While we do not necessarily agree with this view, it is instructive to note that when the analyses are redone excluding federal workers (Table 1, col. 2), the results change only marginally. For evidence of federal government agencies' noncompliance in another area, see George Borjas, Discrimination in HEW: Is the Doctor Sick or Are the Patients Healthy? 21 J. Law \& Econ. 97 (1978).

${ }^{11} \mathrm{We}$ are grateful to a referee for stressing the importance of this point to us. For example, it might be the case that the benefits from noncompliance exceed the costs as far as the firm is concerned, but the costs to workers of not receiving premium pay far exceeds the net benefits to the firm. In this, noncompliance might not arise (even though it is in the firm's best interest not to comply) because employees could potentially offer to pay the firm to comply with the legislation (perhaps by taking a straight-time wage cut or agreeing to smaller wage increases) a sum equal to the firm's net benefits from noncompliance. Such an arrangement would eliminate the firm's gain from noncompliance and would leave the workers better off than they would have been if the firm had failed to comply with the legislation. Of course, workers can first attempt to reduce the firm's net benefit from noncompliance in other ways (see note 13 infra) before resorting to such implicit monetary payments. 
an employer is caught violating the overtime pay provisions; these costs are determined both by the probability of being caught if a violation occurs and by the expected penalty once a violation is identified. The resources available to the Employment Standards Administration to enforce the provisions of the FLSA are minimal, and only rarely does the agency institute investigations on its own. ${ }^{12}$ More typically, investigations result from alleged violations being reported by employees who feel that they have not been paid in accordance with the provisions of the act. This suggests that the costs of noncompliance that an employer perceives he faces will increase as his perception that an employee will report a violation increases. ${ }^{13}$ It also increases with his perception that such a report will be investigated.

Finally, the costs an employer perceives as associated with noncompliance depend upon the expected penalty once a violation is judged to have occurred. Since the penalty for first-time violators who do not falsify their records involves only back payment of the premium pay that is owed to workers (without interest), and the typical settlement involves repayment of substantially less than 100 percent of the funds that are owed, the incentives for firms to comply with the legislation are not very high. ${ }^{14}$ It should not be surprising, then, that we obtained a lowerbound estimate of noncompliance of roughly 10 percent in the completely covered sector. Indeed, the fact that the noncompliance rate is not substantially higher suggests that, while calculations of the benefits and costs from noncompliance influence employers' decisions, they are not the sole determinants. Other factors, such as the desire not to violate government legislation, clearly are important.

From the perspective of employees, the costs of noncompliance include the loss of premium pay they would suffer if the employer failed to pay them an overtime premium of at least time and a half, as called for by the legislation. The benefits include the possibility that a lower "price" for overtime hours would induce an employer to expand his usage of overtime hours. If an employer's demand for overtime hours is elastic with

12 See Ashenfelter \& Smith, supra note 6, for background data on these points.

${ }^{13}$ Employees, of course, must make their own calculations of the benefits and costs to them of reporting noncompliance. While the obvious benefits include the possibility of receiving premium pay for future overtime and back pay to compensate them for their failure to receive overtime premium pay in the past, the costs include the possibility that the employer will use less overtime in the future and/or that he might attempt to retaliate against the "informers" (if he can identify them) by denying them wage increases or promotion opportunities or by laying them off or firing them for cause.

${ }^{14}$ For example, in fiscal year 1977, Labor Department investigations discovered \$88 million of overtime pay premium violations, but only $\$ 33$ million of this total was repaid to workers. See U.S. Dep't Labor, supra note 3, at 21. 
respect to the overtime wage rate, an employee's total labor earnings would be higher if the employer fails to comply with the legislation. In this case noncompliance would yield net benefits to the employee if the increased earnings are sufficient to compensate him for his reduction in leisure hours. Of course, employees also have preferences with respect to the avoidance of violations of government legislation that must be taken into account in the analysis.

To make the discussion a bit more formal, suppose that the net economic benefits that an employer perceives from noncompliance $\left(B_{E}\right)$ and the net economic benefits that employees perceive from noncompliance $\left(B_{W}\right)$ can both be expressed as linear functions of a vector of explanatory variables $(Z)$. Let $\epsilon$ represent the net effect of the sum of employer and employee preferences or tastes for complying with government legislation. Then we can write

$$
\begin{aligned}
& S_{i}^{*}=\left(\alpha_{E}+\alpha_{W}\right) Z_{i}+\epsilon_{i} \\
& S_{i}=1 \text { if } S_{i}^{*}>0 \\
& =0 \text { otherwise. }
\end{aligned}
$$

Here $S_{i}^{*}$ is an unobservable continuous variable that represents the sum of the net economic and noneconomic benefits that individual $i$, who is observed working overtime, and his or her employer would receive from not complying with the legislation. The $\alpha_{E}$ and $\alpha_{W}$ represent vectors of regression coefficients that indicate the marginal effects of the explanatory variables on the net benefits that the employer and the employee, respectively, receive from noncompliance. Since some variables will affect either the employer's net benefits or the employee's net benefits, but not both, some of the coefficients in the vectors $\alpha_{E}$ and $\alpha_{W}$ will be zero. Put another way, the variables that affect $B_{E}$ and $B_{W}$ may well differ.

Although $S_{i}^{*}$ is unobservable, we can arbitrarily scale its cutoff value so that, when the sum of the net benefits from noncompliance is greater than zero $\left(S_{i}^{*}>0\right)$, we observe an individual who is working overtime not receiving a premium that is in compliance with the legislation $\left(S_{i}=1\right)$. Conversely, if the index is less than or equal to zero $\left(S_{i}^{*} \leqslant 0\right)$, the individual will be observed receiving a premium in compliance with the legislation $\left(S_{i}=0\right)$. If we further assume that the $\epsilon_{i}$ can be treated as a normally distributed random variable that is uncorrelated with the $Z_{i}$, equation (1) represents a probit model of the determinants of noncompliance with the overtime premium that can be estimated by standard methods.

Our data on noncompliance are for individuals, and it is natural to ask what variables might enter into $Z$ and influence the probability that a worker working overtime, who is subject to the overtime provisions of the FLSA, does not receive premium pay in compliance with the legislation. 
A group of variables that are likely candidates are available in either the $C P S$ or $Q E S$ samples or can be constructed from other sources, and we discuss each in turn. The noncompliance rate is expected first to decline and then to increase with age of employee. Teenagers have high expected turnover rates; this makes it unlikely that employers will heavily invest in their training and thus that any increase in their turnover rates induced by noncompliance will be costly to the firm. As new entrants, teenagers are also less likely to be aware of the overtime provisions of the FLSA and this, along with their high turnover rates and short tenures, makes it unlikely that they would report any violation and ask for a compliance investigation. Thus the noncompliance rate will likely be high for teens.

Now, as individuals age and develop "permanent" attachment to firms, they accumulate both considerable firm-specific knowledge and knowledge of the FLSA's provisions. Noncompliance with the overtime provisions for these individuals will be costly for the firm; it would be costly to replace them if they quit, and the probability that a FLSA violation will be reported by them is high. However, after some point in time workers become "locked in," their earnings with their current employer exceed their earnings potential elsewhere because of the firm-specific knowledge they have accumulated. This reduces the probability that they will quit in response to noncompliance, which reduces the costs of noncompliance that employers face. These arguments suggest that the noncompliance rate should first decline and then increase with age.

Turning next to the role of an employee's sex, we find that there are two conflicting forces at work on the employer. On the one hand, females have historically had higher turnover rates and lower expected tenure than males and thus received less firm-specific training. This implies that any noncompliance-induced resignations by them would be less costly to firms than resignations by males; as a result, noncompliance rates for females might be expected to be higher than those for males. On the other hand, in a world of growing litigation, employers may be concerned that failure to pay females the legally required premiums would lead to the possibility of sex-discrimination suits; women may be more likely to report noncompliance for this reason, ${ }^{15}$ and this should reduce the noncompliance rate for females. The net effect of these two forces is indeterminate.

Discrimination against nonwhites or Hispanics may manifest itself in higher noncompliance probabilities for individuals from these groups. The fact that some Hispanics are not fluent in English and thus may not be fully aware of the legislation reinforces this effect, as does the possibility that some may be undocumented workers who would be unlikely to com-

15 See note 13 supra. 
plain to authorities about violations of the FLSA. Of course, fear of litigation, or government compliance activities that are targeted at nonwhites, might reduce the noncompliance rates for the group.

Highly skilled individuals are likely both to be costly for firms to replace if they quit and also to be fully aware of their legal rights. As such, higher education levels should be associated with lower noncompliance rates, other things equal. Individuals earning high-wage rates, other things equal, are likely also to have the same characteristics. However, here the firm also has an incentive not to comply, other things equal, since, as an individual's wage rate increases, the benefits (premium savings) from noncompliance also increase. On balance, one might expect that the former effect dominates, and that compliance will increase as employees' wage rates increase. ${ }^{16}$

Noncompliance is also expected to be lower in unionized environments than in nonunion environments. One important role that unions play is to monitor employees' working conditions to assure that both collectively bargained and legally required conditions of employment are satisfied. Not only do unions call violations of legally required conditions to the attention of employers, they also are less reluctant than individual employees-since they fear retribution less-to call these violations to the attention of enforcement agencies.

The $C P S$ and $Q E S$ data both contain information on the industry in which each individual is employed. Other things equal, one should expect that noncompliance rates will be lower in highly concentrated industries for two reasons. First, firms in concentrated industries that face relatively inelastic product demand curves can increase their product prices when faced with having to pay an overtime premium, without fear of losing all of their sales; this reduces the benefits to noncompliance. In contrast, a firm in a highly competitive industry has little control over product price and, faced with the legal requirement to pay an overtime premium, may achieve greater benefits from noncompliance.

Second, from the Hicks-Marshall laws of derived demand, we know that, because the price elasticities of demand faced by firms, in competitive industries are higher than those faced by other firms, ceteris paribus, the wage elasticities of labor demand faced by firms in competitive industries will be higher than those faced by firms in other industries. Noncompliance would thus likely lead to a greater expansion in the usage of overtime hours in these industries than elsewhere. Because of this, the net

${ }^{16}$ Put another way, in structured internal labor markets in which high-wage employees have implicit or explicit long-term contracts, noncompliance, if known, might lead to a reduced supply of new applicants. This would bid up the straight-time wage the firm would have to offer, offsetting any benefits from noncompliance. 
benefits to employees from noncompliance would be higher in competitive industries; this should further increase the probability of observing noncompliance in competitive industries.

Finally, we also expect that noncompliance would be lower in areas in which greater resources are devoted by the government to assuring compliance with the FLSA, since the probability of violations being caught should be higher in such areas. ${ }^{17}$ The Employment Standards Administration (ESA) provided us with data on the total number of FLSA compliance actions undertaken and the total FLSA compliance budget for each of the ninety local ESA area offices in 1978. From these data we were able to aggregate up to state totals, and merge into each CPS individual's record, data on these two measures of compliance activity, each deflated by the number of private and federal nonsupervisory workers in the state, to approximate compliance activity per worker subject to the legislation. ${ }^{18}$

How well are these hypotheses borne out by the data? Table 2 presents estimates of probit models of the determinants of noncompliance for the samples of workers who are subject to the overtime pay provisions of the FLSA with certainty in both the 1978 May CPS and 1977 QES. Noncompliance is defined in the former survey to be failure to receive any premium for overtime hours worked in excess of forty per week, while in the latter survey it is defined to be failure to receive a premium of at least time and a half. One should remember that the sample size in the latter case is extremely small (sixty-nine), and thus it is unlikely that one will

17 The previous hypothesized effects, save for race, assume that government resources devoted to compliance activity are randomly distributed. However, if the government were trying to maximize the effectiveness of its compliance activities, it would assign them in such a way as to maximize the expected number of violations it would uncover (see Ashenfelter \& Smith, supra note 6 , for an elaboration of this point). So, for example, it would investigate primarily low-wage nonunion firms in competitive industries, where violations are likely to occur, rather than high-wage union firms in concentrated industries in which violations are less likely to occur. Clearly, such a rational assignment of government resources would reduce our chances of observing noncompliance being correlated with the other postulated "determinants"; Ashenfelter \& Smith did find some evidence that compliance resources were being assigned nonrandomly. Hence, the empirical estimates we obtain should be understood to represent the product of the interactions between employer and employee and government assignment of enforcement resources. Of course, given the low level of government enforcement activity, we would be surprised to see it substantially alter the pattern of noncompliance (as opposed to the level).

18 The state level was the finest geographic breakdown that could be identified in the CPS data. Since some local offices served more than one state, it was often necessary to aggregate data across several states. As a result, the number of individual states, or state aggregates, for which these totals could be computed is actually thirty-two. We should also note that it was impossible to separate out the resources devoted to minimum wage and overtime pay violation activities. 
TABLE 2

Probit Analysis of Noncompliance: Complete Coverage

Sample, May 1978 CPS ANd 1977 QES Data

(Absolute Value Asymptotic $t$-Statistic)

\begin{tabular}{|c|c|c|c|c|c|}
\hline & \multicolumn{4}{|c|}{ MAY $1978 C P S$} & \multirow{2}{*}{$\frac{1977 Q E S}{(5)}$} \\
\hline & (1) & (2) & (3) & (4) & \\
\hline$Z 1$ & $.006(2.2)$ & $.006(2.2)$ & $.006(2.2)$ & $.005(1.9)$ & $.0641(1.4$ \\
\hline$Z 2$ & $.065(.7)$ & $.066(.7)$ & $.111(1.2)$ & $.111(1.2)$ & $1.276(1.1)$ \\
\hline$Z 3$ & $.022(.3)$ & $-.039(.3)$ & $-.022(.3)$ & $-.023(.3)$ & $1.542(1.7)$ \\
\hline$Z 4$ & $.147(1.3)$ & $.146(1.3)$ & $.094(.8)$ & $.092(.8)$ & $1.901(2.1)$ \\
\hline$Z 5$ & $.157(.5)$ & $.173(.6)$ & $.246(.8)$ & $.265(.9)$ & $\ldots$ \\
\hline$Z 6$ & $.007(.0)$ & $.010(.1)$ & $.059(.4)$ & $.063(.4)$ & \\
\hline$Z 7$ & $-.006(.4)$ & $-.006(.4)$ & $-.007(.4)$ & $-.007(.4)$ & $.010(.7)$ \\
\hline$Z 8$ & $-.018(.2)$ & $-.165(.2)$ & $.005(.1)$ & $.008(.1)$ & $\ldots$ \\
\hline$Z 9$ & $-.057(.7)$ & $-.057(.7)$ & $-.065(.8)$ & $-.063(.8)$ & $\ldots$ \\
\hline$Z 10^{a}$ & $-.016(4.3)$ & $-.016(4.3)$ & $-.015(3.9)$ & $-.015(3.9)$ & $.001(.1)$ \\
\hline$Z 11$ & $-.207(1.5)$ & $-.207(1.5)$ & $-.205(1.4)$ & $.203(1.4)$ & $\ldots$ \\
\hline$Z 12$ & $-.449(5.8)$ & $-.452(5.8)$ & $.364(4.5)$ & $-.367(4.5)$ & $-1.19(1.6)$ \\
\hline$Z 13$ & $.402(3.0)$ & $.401(3.0)$ & & & $-6.983(.0)$ \\
\hline$Z 14$ & $.121(.7)$ & $.122(.7)$ & $.030(.2)$ & $.031(.2)$ & $-9.028(.0)$ \\
\hline$Z 15$ & $.336(2.6)$ & $.336(2.6)$ & $.268(1.9)$ & $.268(1.9)$ & $-.737(.7)$ \\
\hline$Z 16$ & $-.378(3.2)$ & $-.378(3.2)$ & $-.458(3.6)$ & $-.457(3.6)$ & $-1.593(1.4)$ \\
\hline$Z 17$ & $-.551(4.2)$ & $-.550(4.2)$ & $-.622(4.5)$ & $-.622(4.5)$ & $-1.545(1.3)$ \\
\hline$Z 18$ & $-.110(.7)$ & $-.109(.7)$ & $-.294(1.5)$ & $-.293(1.5)$ & $-1.544(1.3)$ \\
\hline$Z 19$ & $-.106(.7)$ & $-.106(.7)$ & $-.168(1.0)$ & $-.168(1.0)$ & $-10.062(.0)$ \\
\hline$Z 20$ & $-.056(.2)$ & $-.056(.2)$ & $-.087(.4)$ & $-.087(.4)$ & $1.132(.6)$ \\
\hline$Z 21$ & $-.74 .868(.8)$ & $\ldots$ & $-.181(.8)$ & 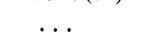 & $\ldots$ \\
\hline
\end{tabular}




\begin{tabular}{|c|c|c|c|c|c|}
\hline$Z 22$ & .. & $-92.134(.9)$ & $\ldots$ & $-.201(.8)$ & $\dddot{042(03)}$ \\
\hline$Z 23$ & & & $\ldots$ & & $.042(0.3)$ \\
\hline$L$ & -1028.0 & -1028.0 & -921.2 & -921.2 & -30.27 \\
\hline$L^{*}$ & -923.9 & -923.9 & -840.8 & -840.8 & -17.66 \\
\hline$N / n$ & $.097 / 3231$ & $.097 / 3231$ & $.090 / 3046$ & $.090 / 0346$ & $.159 / 69$ \\
\hline
\end{tabular}

NoTE. $-L=\log$ of likelihood for binomial model; $L^{*}=\log$ of likelihood function for full model at convergence; $N=$ proportion of sample in noncompliance; $n=$ sample size; $a=$ coefficient has been multiplied by 10 in $C P S$ equations, where (1) (2) = restricted to employees who report being paid by the hour, individuals said to be in noncompliance if they receive no premium pay for overtime; (3) (4) = same as 1 and 2 but restricted to private employees; (5) = restricted to employees who report being paid by the hour, individuals said to be in noncompliance if they receive a premium of less than time and a half; and

$Z 1=$ age.

$Z 2=1=$ male; $0=$ female

$Z 3$ = 1-married, spouse present; $0=$ other

$Z 4=1$ =black; $0=$ other.

$Z 5=1=$ other nonwhite; $0=$ other

$Z 6=1=$ Hispanic; $0=$ other.

$Z 7$ = years of schooling completed.

$Z 8=1=$ reside in central city of standard metropolitan statistical area (SMSA): $0=$ otherwise

$Z 9=1=$ reside in SMSA outside of central city; $0=$ other.

$Z 10=$ usual weekly earnings if reported; $0=$ otherwise in CPS equations; straight-time hourly earnings in the $Q E S$ equations.

$Z 11=1=$ usual weekly earnings not reported; $0=$ otherwise.

$Z 12=1=$ union member covered by union contract; $0=$ otherwise

$Z 13=1=$ government employee; $0=$ otherwise.

$Z 14=1=$ mining; $0=$ otherwise.

$Z 15=1=$ construction; $0=$ otherwise

$Z 16=1=$ durable manufacturing; $0=$ otherwise

$Z 17=1=$ nondurable manufacturing; $0=$ otherwise

$Z 18=1=$ transportation and public utilities; $0=$ otherwise.

$Z 19=1=$ wholesale trade; $0=$ otherwise.

$Z 20=1=$ finance, insurance, and real estate; $0=$ otherwise

$Z 21=$ total number of FLSA compliance actions in the state in 1978/total number of private and federal nonsupervisory employees in the state in 1978

$Z 22$ = total FLSA compliance budget in the state in 1978/total number of private and federal nonsupervisory employees in the state in 1978

$Z 23$ = establishment size. 
observe statistically significant relationships in these data. Nevertheless, since empirical regularities are less subject to challenge when they are replicated in different data bases, we present both sets of estimates.

The dependent variable in each case is the probit transformation of a dichotomous variable that takes on the value of one if the individual failed to receive a premium in compliance with the legislation (as defined above) and zero otherwise. ${ }^{19}$ The explanatory variables in the case of the CPS data include those described above as well as several other control variables. In both data sets, a set of $(0,1)$ variables are included to capture the effect of the major (one-digit) industry group in which the individual is employed. Only a subset of the other explanatory variables was available in the $Q E S$. In particular, since state of residence was not reported in this survey, resources devoted to compliance activities in the state could not be included in the analyses.

Quite strikingly, a number of our hypotheses are borne out. Furthermore, none of the coefficients that is statistically significant is opposite in sign to what we would expect. For example, both data bases indicate quite clearly that noncompliance rates are significantly lower in firms in which unions are present than they are in nonunion firms. Similarly, the probability of noncompliance is significantly lower in heavily concentrated industries, such as manufacturing and public utilities, than it is in less concentrated industries such as mining, construction, wholesale trade, finance, insurance, and real estate. Finally, in accord with our expectations, the probability of noncompliance is significantly negatively related to an individual's earnings level in the CPS data.

Other results are supportive of our model, although less clear-cut. An increase in the level of government resources devoted to compliance activities in a state does appear to reduce the probability of noncompliance; however, this variable is statistically insignificant. The probability of noncompliance is significantly higher for nonwhites than whites in the $Q E S$ data, suggesting that discrimination is present and that this effect dominates over any effect of government enforcement activity. Noncompliance is also seen to increase with age. Results not reported here suggest this relationship occurs primarily for older workers; other things equal, the probability of noncompliance appears to be some 4-6 percent

${ }^{19}$ Our model is of the determinants of noncompliance. Clearly, then, in the case of the $C P S$ data, the dependent variable is measured with error. Whenver it takes on the value of one (no premium), the legislation is not complied with. However, when it takes on the value of zero, this may represent receipt of a premium of time and a half or more (compliance) or receipt of a premium of less than time and a half (noncompliance). Such measurement error may bias the estimates in Table 2; however, it is unclear in which direction the bias will go. 
higher for workers older than fifty-five than for all other workers. As we hypothesized earlier, to the extent that mobility of older workers is limited, older workers may be less likely to institute complaints about nonreceipt of premium pay. Contrary to our prior expectations, however, alternative specifications provided no evidence that noncompliance rates were also higher for teenagers. ${ }^{20}$

Taken together, these results provide support for the view that some employers and their employees, at least implicitly, do make conscious decisions about whether to comply with the overtime provisions of the FLSA-decisions that involve a weighting of the benefits and the costs that both parties incur by such an action. While this might suggest to some that an increase in the overtime premium, which increased the benefits employers receive from not complying with the legislation, would lead to an increased noncompliance rate, we should remind the reader that such an increase also increases employees' economic incentives to report noncompliance. The increased threat of such actions on their part may induce employers to reduce noncompliance. Thus, one cannot predict in advance what the effect of an increase in the overtime premium on noncompliance would be from our results.

\section{Noncompliance in the "Partial Coverage” Sector}

The analyses in the previous two sections were conducted on a subsample of individuals who, we believe with certainty, were subject to the overtime pay provisions of the FLSA. We turn now to the subsample of individuals who can only be assigned a known probability of being subject to the provisions. In this case, estimates of noncompliance cannot be obtained by looking at the proportion of individuals working overtime in the group who fail to receive a premium of time and a half (or any premium, if our conservative definition of noncompliance is being used). Rather, a more indirect method must be used.

Let $C_{i}$ denote the proportion of workers subject to the overtime provi-

${ }^{20}$ In all of the above, compliance is defined conditional on the individual's working overtime. However, the existence of the overtime premium and efforts to enforce compliance with the premium may reduce the probability that individuals actually work overtime. If this occurs, the estimates in Table 2 may be subject to sample-selection bias; we may confound the effect of an explanatory variable on the probability of noncompliance with its effect on the probability of working overtime. See James Heckman, Sample Selection Bias as a Specification Error, 47 Econometrica 153 (1979). Using data on the individuals in the CPS who both did and did not work overtime, we attempted to correct for this problem by estimating a model in which the probability of working overtime and the probability of not receiving a premium were simultaneously determined. Unfortunately, such an approach yielded very few significant coefficients, probably because it is a difficult model to specify accurately. 
sions of the FLSA in industry $i$. We assume that this is equal to the proportion of individuals in each of the retail trade and service industries who are employed in establishments with annual sales of at least $\$ 250,000$ in 1977 . Let $P_{i C}$ equal the probability that a worker subject to the overtime provisions who works overtime in industry $i$ does not receive a premium in compliance with the legislation and $P_{i n}=$ the comparable probability for workers not subject to the legislation. In fact, $P_{i C}$ is the noncompliance rate, the variable which we seek to estimate. It is straightforward to see the probability that an individual working overtime in industry $i$ is not getting paid a premium in compliance with the legislation $\left(\boldsymbol{P}_{i A}\right)$ is given by ${ }^{21}$

$$
P_{i A}=P_{i C} C_{i}+P_{i n}\left(1-C_{i}\right)=P_{i n}+\left(P_{i C}-P_{i n}\right) C_{i} .
$$

This is nothing more than a weighted average of the "noncompliance rates" of the workers who are subject to and not subject to the legislation, with the weights being the proportion of workers subject to and not subject to the legislation. Of course, for workers not subject to the legislation, the term noncompliance does not denote any violation of law; it simply reflects failure to receive the premium called for by the law in the covered sector.

Now suppose, for a moment, that $\boldsymbol{P}_{i C}$ and $\boldsymbol{P}_{\text {in }}$ were constant across individuals and industries. That is, the probability that a worker working overtime who was subject to (not subject to) the overtime pay provisions of the FLSA failed to receive a premium in accordance with the legislation did not vary with either characteristics of the individual or the industry. In this case, equation (3) can be written

$$
\boldsymbol{P}_{i A}=\boldsymbol{P}_{n}+\left(\boldsymbol{P}_{C}-\boldsymbol{P}_{n}\right) C_{i},
$$

where $P_{C}$ and $P_{n}$ are the constant noncompliance rates of workers subject to, and not subject to, the legislation, respectively.

\footnotetext{
${ }^{21}$ Data limitations force us to assume in this calculation that the proportion of employees working overtime in an industry who are subject to the overtime pay provisions of the FLSA equals the reported proportion of employees in an industry who are subject to the provisions $\left(C_{i}\right)$. This assumption may be inappropriate because the usage of overtime hours may vary systematically with establishment size (and hence coverage), although it appears impossible to specify the direction of this relationship. On the one hand, the usage of overtime may be higher in small establishments that are not subject to the legislation because their marginal costs of overtime hours are lower. On the other hand, the size-class exemptions to the FLSA were instituted because small establishments were successfully able to argue they did not regularly schedule overtime hours and that their usage of overtime occurred only in emergencies; if this argument is true, the proportionate usage of overtime would increase with establishment size. The implication of all this is that we may have measured the proportion of employees in an industry working overtime who are subject to the overtime provisions with some error; however, it is impossible to determine whether we systematically have overstated or understated this proportion.
} 
In this situation, it should be clear that if one estimates, for the sample of individuals working overtime, the simple linear probability function model,

$$
d_{i, j}=a_{0}+a_{1} C_{i},
$$

where $d_{i, j}$ takes on the value of one if individual $j$ in industry $i$ is not paid a premium in accordance with the legislation, and the value of zero if he is paid a premium, then one can estimate the noncompliance rate for workers subject to the legislation. ${ }^{22}$ Specifically,

$$
\hat{P}_{C}=\hat{a}_{0}+\hat{a}_{1},
$$

where $\hat{a}_{0}$ and $\hat{a}_{1}$ are the estimated values of $a_{0}$ and $a_{1}$.

Of course, it is not likely that $P_{i C}$ and $P_{i n}$ are constant across individuals or industries or both. The simplest modification is to assume that the probability of noncompliance varies in both sectors with the vector of variables $Z$ that we discussed in the previous section. Suppose that the probabilities that individual $j$, who is employed in industry $i$, does not receive a premium in compliance with the overtime provisions are given, in the two sectors, by

$$
P_{i, C^{\prime}}=P_{0 \mathrm{C}}+P_{1 C} Z_{j}
$$

and

$$
P_{i, n}=P_{0 n}+P_{1 n} Z_{j}
$$

respectively. ${ }^{23}$

Substitution of (6) and (7) into (2) then yields, after manipulation that the probability that an individual with characteristics $Z_{j}$ in industry $i$ who is working overtime fails to receive a premium in compliance with the legislation $\left(\boldsymbol{P}_{i, j,}\right)$ is given by

$$
P_{i \text { iA }}=P_{0 n}+P_{1 n} Z_{j}+\left(P_{0 C}-P_{0 n}\right) C_{i}+\left(P_{1 C}-P_{1 n}\right) Z_{j} C_{i} .
$$

Hence, if one estimates the linear probability function model

$$
d_{i, j}=e_{0}+e_{1} Z_{j}+e_{2} C_{i}+e_{3} Z_{j} C_{i},
$$

${ }^{22}$ While there are well-known statistical problems associated with the linear probability model, estimates obtained from it will be unbiased. We use it here both for expository purposes and because the more appropriate probit or logit models would not permit us to make the necessary linear aggregation across workers subject to and not subject to the legislation.

${ }^{23}$ For expository convenience, in what follows we treat $Z$ and its coefficient vector as single numbers rather than vectors. However, in our empirical work they are treated as vectors. 
the average noncompliance rate for workers subject to the overtime pay provisions of the FLSA in these industries can be obtained from

$$
\hat{P}_{C}=\left(\hat{e}_{0}+\hat{e}_{2}\right)+\left(\hat{e}_{1}+\hat{e}_{3}\right) \bar{Z},
$$

where $\bar{Z}$ is the mean value of $Z$ for individuals in the sample who are subject to the legislation. ${ }^{24}$

Table 3 presents our estimates of the proportion of employees subject to the overtime provisions of the FLSA $\left(C_{i}\right)$ in May 1978 for thirty-six census three-digit retail trade and service industries. ${ }^{25}$ The proportion varied considerably across industries, ranging from 1.00 for department stores to only .04 for barber shops. There were 535 individuals in the May 1978 CPS sample who worked at least forty-one hours during the survey week, reported that they were paid by the hour, were not exempt from the overtime provisions for other reasons, and were employed in one of these industries. These individuals form our partial coverage sample.

Estimates of equations (4) and (9) are found in Table 4 and the implied estimates of noncompliance with the overtime pay provisions one obtains from these results, using equations (5) and (10), are found in Table 5. In each case, noncompliance is defined as failure to receive any overtime pay premium; the estimates therefore likely understate the true noncompliance rate.

The estimates in Table 4 strongly suggest that noncompliance is higher for workers subject to the overtime provisions in the partially covered sector than it is for workers in the complete coverage sector, as we earlier hypothesized. For example, if we use the simplest model which assumes that the probability of noncompliance does not vary with individual or industry characteristics, we estimate that 20.2 percent of individuals working overtime who are subject to the overtime pay provisions in the partially covered sector failed to receive any premium pay for overtime. When we generalize the model to allow noncompliance to vary with characteristics of the individual, the noncompliance rate, evaluated at the mean values of the characteristics, rises to 24.5 percent. These estimates are substantially higher than the 9.6 percent estimate for noncompliance that we observed in the complete coverage $C P S$ sample.

We can also compute estimates of the proportion of individuals in the sample who are not subject to the overtime pay provisions and who did not receive any overtime pay premium for overtime hours. These esti-

${ }^{24}$ Actually, one knows only the mean values of $Z$ for all individuals in the sample, and these are used in the calculations.

${ }_{25}$ These numbers should more precisely be interpreted as the proportion of employees who are not exempt for other reasons (for example, who are not supervisory or outside salespersons) who are subject to the overtime provisions. 
TABLE 3

Estimated Proportion of Employees Covered by the

Overtime Provisions of THE FLSA, MAy 1978:

Retail Trade and Selected Service Industries

\begin{tabular}{|c|c|c|}
\hline $\begin{array}{l}\text { Census } \\
\text { Code }\end{array}$ & $\begin{array}{c}\text { Coverage } \\
\text { Rate }\end{array}$ & Industry Description \\
\hline 607 & .886 & Lumber and building material retailing \\
\hline 608 & .701 & Hardware and farm equipment stores \\
\hline 609 & 1.000 & Department and mail order establishments \\
\hline 617 & .872 & Limited price variety stores \\
\hline 627 & .870 & Miscellaneous general merchandise stores \\
\hline 628 & .922 & Grocery stores \\
\hline 629 & .474 & Dairy products stores \\
\hline 637 & .324 & Retail bakeries \\
\hline 638 & .587 & Food stores, not elsewhere classified \\
\hline 639 & .981 & Motor vehicle dealers \\
\hline 647 & .764 & Tire, battery, and accessory dealers \\
\hline 648 & .784 & Gasoline service stations \\
\hline 649 & .826 & Miscellaneous vehicle dealers \\
\hline 657 & .731 & Apparel and accessories stores, except shoe stores \\
\hline 658 & .540 & Shoe stores \\
\hline 667 & .750 & Furniture and home furnishings stores \\
\hline 668 & .692 & Household appliances, TV, and radio stores \\
\hline 669 & 666 & Eating and drinking places \\
\hline 677 & .815 & Drug stores \\
\hline 678 & .717 & Liquor stores \\
\hline 679 & .887 & Farm and garden supply stores \\
\hline 688 & .882 & Fuel and ice dealers \\
\hline 689 & .285 & Retail florists \\
\hline 697 & .527 & Miscellaneous retail stores \\
\hline 749 & .719 & Automobile services, except repair \\
\hline 757 & .607 & Automobile repair and related services \\
\hline 758 & .607 & Electrical repair shops \\
\hline 759 & .511 & Miscellaneous repair services \\
\hline 777 & .881 & Hotels and motels \\
\hline 787 & .084 & Beauty shops \\
\hline 788 & .040 & Barber shops \\
\hline 789 & .059 & Shoe repair shops \\
\hline 797 & .565 & Dressmaking shops \\
\hline 798 & 686 & Miscellaneous personal services \\
\hline 808 & .631 & Bowling alleys, billiard and pool parlors \\
\hline 809 & .717 & Miscellaneous entertainment and recreation services \\
\hline
\end{tabular}

SouRCES.-Authors' calculations from unpublished tabulations prepared by the U.S. Bureau of the Census from data from the 1977 Census of Retail Trade and 1977 Census of Selected Service Industries. 
TABLE 4

OLS Noncompliance Regressions: Partial Coverage SAMPLE, MAY 1978 CPS*

\begin{tabular}{lcccc}
\hline \hline Variable & $(1)$ & $(2)$ & $(3)$ & $(4)$ \\
\hline CONST & $.642(7.5)$ & $.643(7.5)$ & $-.614(.9)$ & $-.619(.9)$ \\
$Z 1$ & $\ldots$ & $\ldots$ & $.017(2.6)$ & $.018(2.7)$ \\
$Z 2$ & $\ldots$ & $\ldots$ & $.014(.1)$ & $.013(.1)$ \\
$Z 3$ & $\ldots$ & $\ldots$ & $-.344(1.9)$ & $-.357(2.0)$ \\
$Z 4$ and $Z 5$ & $\ldots$ & $\ldots$ & $-.031(.1)$ & $-.020(.1)$ \\
$Z 6$ & $\ldots$ & $\ldots$ & $-.437(1.1)$ & $-.438(1.1)$ \\
$Z 7$ & $\ldots$ & $\ldots$ & $.082(1.8)$ & $.081(1.7)$ \\
$Z 10^{\dagger}$ & $\ldots$ & $\ldots$ & $-.012(1.2)$ & $-.013(1.2)$ \\
$Z 11$ & $\ldots$ & $\ldots$ & $-.225(.6)$ & $-.247(.7)$ \\
$Z 12$ & $\ldots$ & $\ldots$ & $-.336(1.2)$ & $-.333(1.2)$ \\
$C$ & $-.440(3.9)$ & $-.447(3.5)$ & $1.295(1.4)$ & $1.388(1.5)$ \\
$C^{*} Z 1$ & $\ldots$ & $\ldots$ & $-.021(2.4)$ & $0.022(2.5)$ \\
$C^{*} Z 2$ & $\ldots$ & $\ldots$ & $.015(.1)$ & $.016(.1)$ \\
$C^{*} Z 3$ & $\ldots$ & $\ldots$ & $.305(1.3)$ & $.325(1.4)$ \\
$C^{*}(Z 4$ and $Z 5)$ & $\ldots$ & $\ldots$ & $.607(.1)$ & $.053(.1)$ \\
$C^{*} Z 6$ & $\ldots$ & $\ldots$ & $.549(1.1)$ & $.567(1.1)$ \\
$C^{*} Z 7$ & $\ldots$ & $\ldots$ & $-.090(1.5)$ & $-.089(1.5)$ \\
$C^{*} Z 10 \dagger$ & $\ldots$ & $\ldots$ & $.002(.1)$ & $.001(.1)$ \\
$C^{*} Z 11$ & $\ldots$ & $\ldots$ & $-.018(.0)$ & $-.002(.0)$ \\
$C^{*} Z 12$ & $\ldots$ & $.272(.8)$ & $.249(.7)$ \\
$C^{*} Z 21$ & $\ldots$ & $7.546(.1)$ & $\ldots$ & $-82.028(1.3)$ \\
$R^{2}$ & .028 & .028 & .136 & .139 \\
\hline
\end{tabular}

NoTE. $-N=535$ for all equations. Noncompliance was defined in this table as failure to receive any premium pay for hours in excess of forty per week. Numbers in parentheses are absolute value $t$ statistics.

* See Table 2 for variable definitions. All variables are defined as before save $C$, which is the estimated proportion of employees in the industry subject to the overtime pay provisions of the FLSA (see Table 3 ).

$\uparrow$ Coefficient multiplied by ten.

mated noncompliance rates have no normative significance, as these workers are not legally required to receive a premium. Nonetheless, it is interesting to note that they are considerably larger than the noncompliance rates for workers in these industries who are subject to the legislation. Indeed, our estimates of "noncompliance" for these nonsubject workers is 64.2 percent when the probability of receiving a premium is assumed not to vary with individuals' characteristics and 48.5 percent when it is assumed to vary.

One might be tempted to conclude from these estimates that a reasonable estimate of the effect of the FLSA on the probability that workers in these industries who are subject to the overtime provisions are paid a premium is the difference between the proportions receiving premium pay in both sectors. Our estimates would imply then that the FLSA has 
TABLE 5

Estimates of Noncompliance with the Overtime Provisions of the FLSA: Partial Coverage Sample, May 1978

\begin{tabular}{lcc}
\hline \hline Model & $P_{C}$ & $P_{n}$ \\
\hline $\begin{array}{l}\text { 1. Noncompliance constant } \\
\text { within each sector }\end{array}$ & Covered Sector $(\%)$ & Noncovered Sector (\%) \\
$\begin{array}{l}\text { 2. Noncompliance varies } \\
\text { within each sector with } \\
\text { characteristics of the } \\
\text { individual }\end{array}$ & 20.2 & 64.2 \\
\hline
\end{tabular}

SourCE.-Authors' calculations based on the May 1978 CPS Public Use data. Based on the regression results found in Table 4, cols. 1 and 3 .

increased the probability that a worker receives premium pay for overtime by between twenty-four (48.5-24.5) and forty-four $(64.2-20.2)$ percentage points.

Such a conclusion would be incorrect, however, for at least two reasons. First, the presence of a covered sector may well affect the probability that establishments in the noncovered sector pay an overtime premium. ${ }^{26}$ Thus, estimates of the difference between noncompliance rates in the covered and noncovered sectors tells us little about the effect of the legislation on the probability that workers subject to the legislation are paid a premium. Second, independent of the above problem, there is no reason to presume that the probability that noncovered (small) establishments pay a premium is an accurate estimate of the probability that covered (larger) establishments would pay an overtime premium in the absence of the legislation. Our estimates simply cannot be used to infer anything about the quantitative effect of the FLSA on the proportion of workers receiving premium pay for overtime in this sector.

Finally, one can recover estimates of the marginal effects of the various

${ }^{26}$ One might argue that, as the proportion of individuals covered by the legislation increases, the noncompliance rate in this sector will fall, since both employees and employers will be more likely to be aware of their being subject to the legislation. In addition, if labor markets are at all competitive, one could hypothesize that an increase in the proportion of workers subject to the legislation would increase the probability that employers not subject to the legislation would have to pay overtime premiums to attract workers. While it would be desirable to test these hypotheses, if one allows both $P_{n}$ and $P_{r}$ to vary with $C$, the resulting estimating equation would be underidentified and one would not be able to obtain an estimate of either $\boldsymbol{P}_{r}$ or $\boldsymbol{P}_{n}$. We did estimate some equations in which only $\boldsymbol{P}_{C}$ was allowed to vary with $C$. While these equations yielded estimates of $P_{c}$ that were higher than those in Table 5 , one can show that, if the probability that premium pay for overtime is received in the noncovered sector increases with $C$, then such estimates of $P_{r}$ will be biased upward. 
TABLE 6

ImPlied Partial Derivatives*

OlS Noncompliance Results, Partially Covered Sample

\begin{tabular}{lllc}
\hline \hline $\begin{array}{l}\text { Expected } \\
\text { Impact }\end{array}$ & & \multicolumn{1}{c}{ Variable } & \multicolumn{1}{c}{$\delta \hat{P}_{C} \mid \delta Z$} \\
\hline- then + & $Z 1$ & Age & $-.004(1.3)$ \\
$?$ & $Z 2$ & Sex $(1=$ male $)$ & $.029(.4)$ \\
$?$ & $Z 4 \& Z 5$ & Race (1=nonwhite) & $.033(.3)$ \\
+ & $Z 6$ & Hispanic (1=yes) & $.129(.7)$ \\
- & $Z 7$ & Education & $-.008(.4)$ \\
- & $Z 10$ & Earnings & $-.012(2.3)$ \\
- & $Z 12$ & Union & $-.084(.8)$ \\
- & $Z 22$ & Compliance activity & $-82.028(1.3)$ \\
\hline
\end{tabular}

* Derived from the estimates in col. 4 of Table 4. Numbers in parentheses are absolute value $t$ statistics.

explanatory variables on the noncompliance rate for workers subject to the overtime pay provisions in this sample from

$$
\partial \bar{P}_{C} / \bar{Z}=\left(\hat{e}_{1}+\hat{e}_{3}\right) \text {. }
$$

These estimates are presented in Table 6 for a number of the explanatory variables; their expected signs are summarized in the first column. Although most of these effects prove not to be statistically significantly different from zero, perhaps because of the smaller sample sizes in the partially covered sample, it is gratifying to observe that the pattern of effects is quite similar to that which we observed in the complete coverage $C P S$ sample. In particular, the noncompliance rate in this sector is higher for males than females and for nonwhites than whites, is lower for union members than nonunion members, and declines with an individual's earnings and education level and with the level of resources that the government devotes to compliance activity. Each of these relationships was also observed in the complete coverage sample.

\section{Concluding Remarks}

The evidence presented in this paper strongly suggests that noncompliance with the overtime pay provisions of the FLSA is a nontrivial problem. Our analyses of the May 1978 CPS data indicated that at least 9.6 percent of individuals who worked more than forty-one hours in the survey week and who we believe were subject to the FLSA's overtime provisions with certainty failed to receive any premium pay for overtime hours. Moreover, from our analyses of the partial coverage CPS sample, we inferred that over 20 percent of the people working overtime who were 
subject to the overtime pay provisions in those industries in which sizeclass exemptions existed failed to receive any premium. Finally, our analyses of the 1977 Michigan $Q E S$ data indicated that almost 16 percent of the individuals who worked overtime and who we believe with certainty were covered by the overtime provisions failed to receive a premium of time and a half. Together, these analyses strongly suggest that 10 percent would be a highly conservative estimate of the noncompliance rate with the overtime pay provisions of the FLSA. Such a noncompliance rate would substantially moderate the positive employment effects generated by any future increase in the overtime premium.

Our analyses also provide some support for the view that decisions about whether to comply with the overtime pay provisions of the FLSA are at least partially based on the benefits and costs that are associated with noncompliance. To the extent that increasing the overtime premium would increase the benefits employers perceive from noncompliance, this might lead to an increase in noncompliance. If this occurs, the employment effects of an increase in the premium would be further moderated. Of course, an increase in the overtime premium would also increase employees' economic incentives to report noncompliance to enforcement authorities. The increased threat of such actions on their part might induce employers to reduce noncompliance. Thus, our results unfortunately do not permit us to predict what the effect of an increase in the overtime premium on noncompliance would be. 